\title{
INNOVATIVE DESIGN IN FACTORY - NEW METHODS TO GO FROM CLOSED TO EXPANDABLE PRESCRIPTIONS AT THE SHOP FLOOR LEVEL
}

\author{
Harlé, Honorine (1); Le Masson, Pascal (1); Weil, Benoit (1); Hooge, Sophie (1); Levillain, Kevin \\ (1); Bulin, Guillaume (2); Menard, Thierry (2)
}

1: MINES ParisTech; 2: Airbus, Saint-Nazaire

\begin{abstract}
This paper explores the question of the design activity at the shop floor level. The design activity has been confined for a large part in the design and the methods office. However, a certain form of design adapted to the factory remains. It is necessary to solve the problems which appear during the manufacturing process and to improve the productivity. However another form of design can emerge; it has a stronger impact on the factory, since the rules of the manufacturing system are modified under its effect. The paper studies 21 cases of design in the Airbus factory at Saint-Nazaire. It shows that the design activity does exist at the shop floor level. It characterizes this activity distinguishing two types of design which can co-exist in a factory. It shows that the type of results reached is not the same according to the type of design implemented.
\end{abstract}

Keywords: Industry 4.0, Design management, Design practice, Robust design

\section{Contact:}

Harlé, Honorine

MINES ParisTech

Centre de Gestion Scientifique

France

honorine.harle@mines-paristech.fr

Cite this article: Harlé, H., Le Masson, P., Weil, B., Hooge, S., Levillain, K., Bulin, G., Menard, T. (2019) 'Innovative Design in Factory - New Methods to Go from Closed to Expandable Prescriptions at the Shop Floor Level', in Proceedings of the 22nd International Conference on Engineering Design (ICED19), Delft, The Netherlands, 5-8 August 2019. DOI:10.1017/dsi.2019.122 


\section{INTRODUCTION: THE QUESTION OF THE DESIGN IN FACTORY}

Historically, the manufacturing system is divided to optimize both the design of the products and the processes and the manufacturing activity. Thus designing is a task devoted to the engineering design and the engineering manufacturing offices; the factory is in charge of the production. Throughout the $\mathrm{XX}^{\text {th }}$ century, the successive managerial streams brought methods and tools in the factory to improve its performance, and to solve the problems that appear locally during the manufacturing process. They concern, according to the period, quality and default problems on the machines and on the products, time management, blockages in the line... They are adapted to the constrained environment characterizing the manufacturing system. The implementation of these methods, resulting in a decision between several possible solutions, can be considered as a first degree of design.

Nevertheless, another type of design was observed in the Airbus Saint-Nazaire's factory (France), at the shop-floor level. It seemed more innovative and used different methods and organizations to develop a solution. It revealed positive and surprising effects on the factory, in terms of performance and on the evolution of the system of rules of the manufacturing. This article studies the experiment in this factory that occurred between 2013 and 2018, and explores the existence and the characteristics of a more innovative design at the shop-floor level.

\section{AIM OF RESEARCH}

The paper aims at answering the following questions:

- What is an innovative design in a factory?

- What are the differences between an innovative form of design and the one commonly implemented in factory?

- To what extent is it useful and possible to deploy such an innovative design in the very constrained manufacturing environment?

\section{METHODOLOGY}

The work is based on a research partnership between the European aeronautic company Airbus in the Saint-Nazaire's factory, in France, and the Centre de Gestion Scientifique, a research centre of Mines Paristech, in Paris, between 2013 and 2018. The Saint-Nazaire site is located in Britain (France) and aims at assembling, equipping and testing the forward and central fuselages of the planes. A high degree of prescription, and a tightened framework of standards and norms specific to the aeronautical sector characterize the factory.

To address the later questions, a literature review is presented to characterize what the design regimes in a factory are, and what characteristics they have. A table of criteria is derived from this literature review. Then, the Airbus' experiment intends to verify empirically the existence of these regimes. Three case studies of design are examined through the table of criteria. A quantitative analysis on the whole sample (30 cases of design) aims at looking at the effect of the regime. Finally, a discussion is lead about the innovative design in factory. It opens some perspectives on the implications of this type of design.

\section{LITERATURE REVIEW: CHARACTERIZING THE REGIMES OF DESIGN IN FACTORY}

\subsection{The dominant regime of design in factory}

The dichotomy between the design and the production lets a place for a certain form of design in the manufacturing. The design in factory consists in tackling at the shop-floor level the various problems that appear during the manufacturing process (quality problems, blockages, defaults on a machine, delays, etc.), proposing an adapted solution. The design activity is not ordered by the engineering manufacturing design office, nor the engineering design office. It takes its roots directly in production. One of the means of addressing the need of design at the shop floor level is to encourage the employees' innovative behaviour. "The employee innovative behaviour is defined as the intentional creation, introduction, and application of new ideas within a work role, group, or organization in order 
to benefit role performance, the group, or the organization" (West and Farr, (1989)). In other words, the stake is to give to the operators of production the capability to design a part of the process for its improvement. In this line, the bricolage is a form of design often described as improvisation, consisting in "assembling elements based on simple rules in order to yield an original composition" (Duymedjian and Rüling (2010)). Although the bricolage does not require, by nature, more resources than in the present situation, and is relevant for problem solving, it can suffers from a potential lack of recognition and of institutionalization, especially in a sector very normalized where the processes are very standardized (E Cunha and Da Cunha (2018). Other methods try to capture the creativity of employees, generally in a participative approach. The ideation phase is viewed as particularly important process in which the employees have to be implied, and various types of suggestion systems exist to gather their ideas (Vanharanta (2018), Fairbank and Williams(2001)). Places devoted to the collection of ideas (boxes, intranet...), rewards, or contests (Ikävalko and Lempiälä (2019); Adamczyk, Bullinger and Möslein (2012)) are some of the means existing to support this phase.

In all these approaches, the design remains a problem solving approach, and the goal is to take the good decision among several choices of solutions. The framework is given, the problem is local, and the solution is integrated to the framework. If the productive system is thought as a system of rules, each of them describing how a process should be carried on, the system is the coordinated set of rules to produce the final good. The rules are valid if the environment is stable and controlled. This system can suffer from two drawbacks: it is composed by two many rules which are not well coordinated, or on the opposite, there is not enough rules to make a good prescription. With a problem solving approach, the solution just compensates one or the other of these drawbacks. There is no renewal of the prescription, the system of rules is considered as given. Thus, the solution embodied in the system, as a patch, and its impact is controlled.

This paragraph defines a first regime of design. A regime of design is understood as a combination of rules giving a unified way of practicing design, and a set of methods of design having the same effect on the productive system. The later regime can be called "the closed prescription regime of design", stressing the conservative effect of the design on the system of rules. This regime is coherent with an industrial context. Indeed this approach represents a minimization of resources of time and triggers on a guideline to quickly return to a stable situation. In that sense, the regime can be qualified as a conservative one, and is expected in a factory.

\subsection{Another type of design is suspected}

The literature on design shows that designing solutions does not only refer to a mere decision between options driven by an adequate criterion. On the opposite, it relies on another process encompassing the generation of possible solutions itself (Lu and Conger (2007)).

According to Rittel (1977) the traditional approach to solve the problems is not adapted to the reality. The process to treat the appearing questions should rely on another logic (Shin et al. (2003)). Schön (1987) notices that a problem solving process comes out once the problem is itself well defined, and once several solutions to solve it have been proposed. The design helps to overcome the problem setting. In the same way, Dorst (2006) insists on the interpretation of the problem: the view of the designer leads to a co-evolution of the design problem and the design solution. Dorst (2006) thus presents the design of a solution as a discursive activity through paradoxes. Hatchuel (2001) explains that the description of a design task as a problem to be solved does not take into account the expanded solutions, and that a design task is "beyond problem solving".

Here the prescription is modified or even enriched when a new problem appears. Indeed the rules are changed during the design process. One can easily think that the impact of such an expandable regime is significant on the present system. The nature of the result, comparing to the classical design, in a closed prescription, is different. It seems to be more robust to an unstable environment, and looks to be innovative in terms of rules created.

This regime is, to a certain extent, unexpected in a factory. Its conditions of existence are not easy to gather: it supposes for instance time, a good knowledge of the production line, an awareness of the opportunities to take, and a high level of designing skills of the employees. Last but not least, it makes the system endogenously regenerating, contrary to the former paradigm of stability. This regime of design is qualified as a regime of "expandable prescription", by reference of the capacity of the regime to expand, i.e. generate new rules for the system. 


\subsection{6 criteria characterizing the regimes}

The literature highlights the fact that two regimes of design theoretically co-exist. The aim is now to find a framework listing the properties on which the two regimes differ one from the other. This list is organized according four categories. A more precise description of the criteria is given in the Table 1. (cf Appendix).

- The collective organization: for instance, the team is a multi-functional team, its members are experts (Scott-Young and Samson (2008)) vs there are non-expert of the problem, there are people usually not directly implied in this production process (Somech and Drach-Zahavy (2013)).

- The characterization of the problem: the problem is well-defined and delimited, the constraints are known, even for difficult problems solved by sophisticated algorithms (for instance Blazewicz et al. (1996) vs the problem is a phenomenon, poorly understood, a wide question, which needs to be measured carefully (Voss and Post (1988)).

- The approach to solve the problem: a problem solving approach is used, without any iterations nor tests during the process. It is linear, a succession of phases and decisions (Schmidt et al. (2009)), vs tests (partial or total) are carried on to discover new potential parameters of action and improve the solution (Simonsen and Hertzum (2010)).

- The characterization of the solution: the solution is definitive and does not modify the rules of the system $v s$ the solution is challenged and improved Rittel (1977).

Moreover, a criterion is added. It concerns the effect of the design solution on the factory:

- The type of success reached: a short or long-term effect. A case can be considered as a success of type 1 if, once implemented, the solution was quickly given up, or rejected in practice by the employees. A case is classified as a success of type 2 if the solution was adopted in the manufacturing process in the long term, or re-used to design a new solution for another problem.

To conclude, this literature review describes two regimes of design. They depict two ways of reasoning from a same initial question and to propose a solution. The first one, conservative, seems to be compatible with the traditional industrial system (closed prescription). The second one (expandable prescription) is less expected in such a constrained context and appears, a priori, difficult to implement. However, it can be interesting and relevant for the contemporary context, unstable, with lots of products, mass customization, and technological challenges.

\section{RESEARCH QUESTIONS AND HYPOTHESIS ON THE EXISTENCE OF AN INNOVATIVE DESIGN IN FACTORY}

The literature review unearths two theoretical design regimes. Then, the research questions deal with the empirical existence of these two regimes.

- RQ1: Can we find, in practice, an innovative design, distinct from the conventional regime of design generally observed in factory?

- RQ2: Do the methods and the performance correspond to the theoretical description given by the literature?

- RQ3: Are the two regimes compatible or in opposition? Are they exclusive one from the other?

Based on the previous framework, two hypotheses are proposed:

- H1: There are, at least, two regimes of design in factory. The first one is conventional, the second one, more innovative.

- H2: According to the design regime, the level and the type of performance reached vary.

\section{ANALYSIS}

\subsection{Data}

The data were collected between 2013 and 2018 by one of the practitioners responsible for the question of the design at the Saint-Nazaire's manufacturing site. Then, the details of the cases were registered during several semi-directive interviews. The practitioner ordered 30 cases of design that he witnessed according to their success. He drove himself a part of them; the remaining cases appeared during the manufacturing process and were presented to him ex-post. 


\subsection{Cases study: highlighting the two types of regimes of design}

In this section, three cases were selected to illustrate the approach followed to find a solution. They were chosen according to their relevance to illustrate the design regime. Moreover, they were selected to show the diversity of the fields of application of the design in factory.

\subsubsection{Case 1: closed prescription - listing and implementing golden rules to improve quality}

The final stage of the manufacturing process is a quality control that gives a grade for each product leaving the factory, according to the quality criteria fixed.

The direction of the Airbus Saint-Nazaire's factory decided to increase the general quality of the products at this stage. The direction wanted to raise the quality grade of the planes at the final stage. For that purpose, a workshop was organized. It gathered, during a whole day, all the managers responsible for the successive stages of the production. They were asked to discuss about their way of managing quality in their production workshop. Then, they should debate about their good practices, and should finally set up a list of ten "golden rules". These rules were adopted and implemented by the managers gathered at this one-day workshop. Though, the average quality grade at the final stage did not increase.

This case is typical of the closed prescription regime. In their effect, the golden rules do not modify the system of rules of the factory. More concretely, there is a tool called "golden rules" which is used to solve a problem very local, namely the quality grade at the final manufacturing stage. The rules concerning more generally the quality process or the way of evaluating, controlling, apprehending quality and its management are unchanged. Thus the list of golden rules is a tool in compliance with the system of rules, and does not re-question it.

Moreover, in its method and its organization, the case has most of the criteria of a closed prescription regime. The quality question was reduced to a problem of grade of quality. There was no measure but the quality grade to detect defaults in the quality management. To tackle the problem, a tool was chosen, addressed to the managers, and implemented. Here, the collective was coherent with the production process: it gathered the production managers for each stage of the process. The solution was set up in one meeting. At the end of the meeting, the agreement on the rules was considered as suitable for the situation. However it seemed more the end of a negotiation than a collective design of rules that would increase the quality. Indeed, the managers agreed on the rules which would not be too restrictive or binding for them. The fact that the grade did not improved did not encourage a revision of the golden rules or a research for another method to tackle the problem.

The completion of the 16 criteria is given in more details in Table 2.

\subsubsection{Case 2: expandable prescription - internal notes}

When a product or a part of a product is detected as not compliant with the standards given by the engineering office, a process of the non-conformity treatment is implemented. A file is opened, with pictures, dimensions, description of the problem etc. The file is sent to the engineering office, which processes the case through successive steps (for instance, the address to the appropriate engineering team, the proposition of a solution, the calculus of the properties of the new solution, the validation of the solution...). At the end, the solution is executed in the production. Although this process is efficient on a quality point of view, it is very long and suffers of delays due to an accumulation of cases to be treated. A team was gathered to address the problem. The team spent a few meetings a launched analysis to measure the problem and understand it, to elaborate and test a new process. Finally, the process of the non-conformity treatment changed: it became shorter for several redundant cases. They do not need to follow all the steps because they often occur and the operators at the shopfloor level already know the final solution. Consequently, the problem of blockage and delays disappeared.

This case is representative of the design regime in expandable prescription. The rule on the nonconformity treatment was improved. The role of the operators detecting the non-conformity is also changed: they know and say if the problem is redundant and if solution is already known. They drive the case in the short or long process. In the method used to design the improvement, some criteria appeared to be crucial for the design approach. The team was composed of 5 people. One of them was an employee of a external firm, who insisted to precisely scan in real-time the path followed by the internal notes. This process had never been entirely measured by the past. He discovered that the theoretical of treating the notes was different from the factual one. Several workshops were necessary 
to investigate and treat the case, to find the idea, and to test the solution: the case stood for one year, with 2 meetings per week in average. The completion of the criteria is given in details in Table 2.

\subsubsection{Case 3: hybrid - monitoring the quality}

In order to raise the level of the average quality grade at the final stage of the production line ( $c f$ case 1), goals were assigned and adapted to each manager (between 5 and 10 people) according to their results and their position in the production line. The findings and the implementation of the goals took 6 months, with one meeting a week. The production managers knew their own potential of progression. The final quality grade increased, and the improvement process is still in action since the targets are still reviewed and updated.

This case is hybrid, in the sense that it takes some key elements in the closed prescription regime and other elements in the expandable prescription one. For example, the team was built in accordance with the organization of production line, with one manager for one part of the production (closed prescription). There was no one from another field, for example linked to quality but not directly implied in production. Moreover, the computation of the Pareto diagrams to improve the quality is a famous method just adapted to the case and implemented (closed prescription). However, collectively and iteratively defining and measuring the process, to find out where the quality problem could come from, is more a characteristic of an expandable prescription regime. The solution, not only the result for the criteria but the criteria themselves, is still in improvement (expandable prescription). The completion of the criteria is given in Table 2 .

Table 2. The criteria for the 3 case studies

\begin{tabular}{|l|r|r|r|r|}
\hline Category & criterion & \multicolumn{1}{c|}{ case 1 } & \multicolumn{1}{c|}{ case 2 } & \multicolumn{1}{c|}{ case 3 } \\
\hline $\begin{array}{l}\text { collective } \\
\text { organization }\end{array}$ & 1 & 0 & 1 & 0 \\
\cline { 2 - 5 } & 2 & 0 & 1 & 0 \\
\cline { 2 - 5 } & 3 & 0 & 1 & 0 \\
\cline { 2 - 5 } $\begin{array}{l}\text { characterization of the } \\
\text { problem }\end{array}$ & 4 & 1 & 1 & 1 \\
\cline { 2 - 5 } & 5 & 0 & 1 & 1 \\
\cline { 2 - 5 } & 6 & 0 & 1 & 1 \\
\cline { 2 - 5 } & 7 & 0 & 1 & 1 \\
\hline approach & 8 & 0 & 0 & 0 \\
\cline { 2 - 5 } & 10 & 0 & 0 & 0 \\
\cline { 2 - 5 } & 11 & 0 & 1 & 1 \\
\cline { 2 - 5 } & 12 & 0 & 1 & 1 \\
\hline solution & 13 & 0 & 1 & 1 \\
\cline { 2 - 5 } & 14 & 0 & 1 & 1 \\
\cline { 2 - 5 } & 16 & 1 & 1 & 1 \\
\cline { 2 - 5 } & 16 & 0 & 1 & 0 \\
\hline
\end{tabular}

Legend: 0 corresponds to the closed prescription; 1 to the expanded prescription

\subsection{Quantitative analysis: the long term effect of an innovative design}

This analysis intends to know if there is a link between the type of success reached and the design regime (closed or expanded prescription).

\subsubsection{Step 1: from a multi-criteria list to a regime of design: the "impure" expandable regime}

The design regime is binary, following the categorization "closed" or "expandable prescription". It results in the completion of the table of criteria previously presented. However the cases have not often all their criteria belonging to the same regime. Even for the hybrid cases (the cases who check criteria of both the two regimes), there are never more than 5 criteria following the opposite regime. 
Then, the rule to classify a case in its design regime is the following: the regime of a case is the regime for which the case checks at least 11 criteria.

This step is significant for the analysis. In fact, on 18 cases of expandable prescription, 6 have between 3 and 5 criteria belonging to the closed prescription regime, and 4 are "pure", i.e. have all their criteria belonging to the expandable regime. Hence, the regime called "expandable prescription" can be considered as a mixed regime, borrowing some characteristics to the conservative regime (closed prescription). This is certainly due to the environment of the factory, highly prescribed, with lots of constraints. In this type of context, a "pure" expandable regime could be difficult to implement, or even undesirable in certain cases.

\subsubsection{Step 2: the effect of the design and the type of the regime are non independent}

In the following part, it is asked if there is independence between the two variables: the type of the regime of design (closed or expandable prescription) and the type of success reached (type 1 or type 2). The data used are the 30 cases, their design regime (see the section below) and their type of success (described below).

A chi-square test of 1 degree of freedom is implemented, at the $5 \%$ level.

Hypothesis:

H0: The design regime and the type of success are independent;

H1: The design regime and the type of success are not independent.

Results:

The test gives a calculated statistics equal to 16.69 , which is higher than the theoretical statistics 7,88 . The p-value is equal to $4,39.10^{-5}$.

Conclusion: $\mathrm{HO}$ is rejected at the $5 \%$ level.

\subsection{Results of the analysis: an innovative design with robust effects was implemented in the Saint-Nazaire's factory}

First, this work enlightens the forms of design activity that occur in a factory. Indeed, design problems happen during the manufacturing process. The cases show, whatever the regime, that a design approach is necessary to solve the problems locally or to tackle broader questions in the factory.

Second, the three cases study highlights the difference between the types of design. This qualitative analysis and the completion, for the 27 other cases, of the criteria that finally determine the regime validate the hypothesis 1 (there are, at least, two regimes of design in factory). The relation to the prescription plays a determinant role to differentiate the type of design: the first design appears when the rules are given, the uncertainty is considered as normal during the process, and several solutions can be chosen; the problem is to find the optimal one. The second type of design relies on he exploration of the unknown. Indeed, the rules are not all written, or if it is the case, they can be rewritten, improved or cancelled and they can go beyond the former rules. The result of the design task finally lies in determining the new rules of the system. That finding validates the hypothesis 2 (According to the design regime, the level and the type of performance reached vary).

Third, the analysis of the cases points out the fact that the two regimes of design are not exclusive. On the one hand, in the same factory, the two types of design co-exist. On the other hand, in the same solution, some of the variables can differ in their state from the general regime of the solution. The cases of expandable prescription tend to be hybrid, and mix the practices from the regime "closed prescription" with those of the regime "expandable prescription". It could be a specificity of the design in factory.

\section{DISCUSSION}

\subsection{The consequences of an innovative design approach in the factory: new parameters and new rules appear}

Two main facts come out from the observation of the effects of the design in the expandable prescription regime: the finding of new parameters and the appearance of new rules.

Indeed, new parameters that were forgotten or even unknown by the past emerge. The exploratory approach encourages the clear comprehension of the phenomenon, and requires the measure of new variables. These new dimensions can be interpreted as new levers of actions or new axis of 
performance. The design then captures the changes in the number of dimensions by adding new rules relative to the new parameters, changing the prescription. Consequently, the former rules become obsolete.

To sum up, the innovative design plays a role in unearthing the degrees of freedom that were ignored in the present system of rules. It generates a place for the production operators to improve themselves the prescription.

\subsection{The relevance of the expandable prescription regime}

The experiment also shows that the type of success of the design varies according to the regime of prescription. In the closed prescription, the solution prepared as a recipe, or a patch, to solve the problems with an economy of resources. It holds because the system is closed, since stable and predictable. Nevertheless, if the environment changes, the solution is fragile: it cannot resist to the random events that affect the manufacturing system, in terms of change of products, change of processes and change of technologies. On the contrary, the regime in expandable prescription, very expansive for a closed world, is more adequate for an unstable environment. The solutions designed are more robust to the randomness of the context.

In the context of rapid evolution of technologies, of intensive transformation of the products, it seems to be useful to have such a robust design activity able to absorb the shocks of the environment. Indeed, industry seems to enter a new paradigm (Industry 4.0, smart industry...). The manufacturing system is reorganized around new technologies (big data, IoT), to become smarter, more digitalized, more automatized. However, the general scheme does not change: the factory is in charge of the production, of the good execution of plans given by the engineering office. It is not the place to develop a design activity, since all the processes are very constrained, embodied in a system of rules. This observation remains very accurate even in an automatized factory: all the production process is entirely designed upstream. Though, adding an innovating design capacity to the factory could be relevant for industry to be resilient to the shocks and the future changes of various nature (economical, technological, environmental...).

\section{MANAGERIAL IMPLICATIONS AND PERSPECTIVES: DESIGNING AT THE SHOP FLOOR LEVEL}

The variables characterizing the two different regimes of design show that designing is an approach that needs to be triggered. The article, in the list of criteria, suggests that there are two types of management to drive the design activity in a factory.

Pursuing this idea, the results let think that designing is a skill that a factory can benefit via the designing skills of the managers as well as the production operators. The factory can give to itself the ability to regenerate its own rules, and its own prescription. This article presents a first comprehension of the design process in practice and of its methods. The way of formulating and measuring the problems, gathering people in teams, exploring and testing the solutions need to be organized and controlled.

\section{REFERENCES}

Adamczyk, S., Bullinger, A.C. and Möslein, K.M. (2012), "Innovation contests: A review, classification and outlook”, Creativity and Innovation Management, Vol. 21 No. 4, pp. 335-360. https://doi.org/10.1111/caim.12003

Dorst, K. (2006), "Design problems and design paradoxes”, Design issues, Vol. 22 No. 3, pp. 4-17. https://doi.org/10.1162/desi.2006.22.3.4

Błażewicz, J., Domschke, W. and Pesch, E. (1996), “The job shop scheduling problem: Conventional and new solution techniques", European journal of operational research, Vol. 93 No. 1, pp. 1-33. https://doi.org/10.1016/0377-2217(95)00362-2

Duymedjian, R. and Rüling, C.C. (2010), “Towards a foundation of bricolage in organization and management theory”, Organization Studies, Vol. 31 No. 2, pp. 133-151. https://doi.org/10.1177/0170840609347051.

Fairbank, J.F. and Williams, S.D. (2001), "Motivating creativity and enhancing innovation through employee suggestion system technology", Creativity and innovation management, Vol. 10 No. 2, pp. 68-74. https://doi.org/10.1111/1467-8691.00204 
Hatchuel, A. (2001), "Towards design theory and expandable rationality: the unfinished program of herbert simon", Journal of management and governance, Vol. 5 No. 3-4, pp. 260-273. https://doi.org/10.1023/A:1014044305704

Ikävalko, H. and Lempiälä, T. (2019), "Innovation contests, routine dynamics and innovation management", Creativity and Innovation Management. https://doi.org/10.1111/caim.12299

Lu, S.C. and Conger, A. (2007), "Supporting participative joint decisions in integrated design and manufacturing teams", In Advances in Integrated Design and Manufacturing in Mechanical Engineering, Vol. 2 , pp. 322. Springer, Dordrecht, https://doi.org/10.1007/978-1-4020-6761-7_1

Cunha, M.P.E. and da Cunha, J.V. (2018), Bricolage in organizations: concept and forms. In Current topics in management (pp. 59-78). Routledge.

Rittel, H.W. (1977), On the Planning Crisis: Systems Analysis of the” first and Second Generations.”. Institut für Grundlagen der Planung IA, Universität Stuttgart

Scott-Young, C. and Samson, D. (2008), "Project Success and Project Team Management: Evidence from Capital Projects in the Process Industries", Journal of Operations Management, Vol. 26, pp. 749-766. http://dx.doi.org/10.1016/j.jom.2007.10.006

Shin, N., Jonassen, D.H. and McGee, S. (2003), "Predictors of well-structured and ill-structured problem solving in an astronomy simulation". Journal of research in science teaching, Vol. 40 No. 1, pp. 6-33, https://doi.org/10.1002/tea.10058

Schön, D.A. (1987), “Jossey-Bass higher education series". Educating the reflective practitioner: Toward a new design for teaching and learning in the professions. Jossey-Bass, San Francisco, CA, US.

Schmidt, J.B., Sarangee, K.R. and Montoya, M.M. (2009), "Exploring new product development project review practices", Journal of Product Innovation Management, Vol. 26 No. 5, pp. 520-535. https://doi.org/10.1111/j.1540-5885.2009.00678.x

Simonsen, J. and Hertzum, M. (2010), “Iterative participatory design”, Design Research: Synergies from Interdisciplinary Perspectives. 1 edn, Vol. 1, Routledge, London, pp. 16-32.

Somech, A. and Drach-Zahavy, A. (2013), "Translating team creativity to innovation implementation: The role of team composition and climate for innovation", Journal of management, Vol. 39 No. 3, pp. 684-708. https://doi.org/10.1177/0149206310394187

Vanharanta, O. (2018), "Whose responsibility is it anyway? Competing narratives of suggestion system change", Creativity and Innovation Management, Vol. 27 No. 3, p. 244-254. http://dx.doi.org/10.1111/caim.12286

Voss, J. F. and Post, T. A. (1988), "On the solving of ill-structured problems”. In Chi, M.T.H., Glaser, R. and Farr, M.J. (Eds.), The nature of expertise (pp. 261-285). Lawrence Erlbaum Associates, Inc, Hillsdale, NJ, US.

West, M. A. and Farr, J. L. (1989), "Innovation at work: Psychological perspectives”, Social Behaviour, Vol. 4, pp. $15-30$

\section{APPENDIX}

Table 1. The characteristics of the regimes of design

\begin{tabular}{|l|l|l|l|}
\hline category & n. & closed prescription & expandable prescription \\
\hline $\begin{array}{l}\text { Collective } \\
\text { organization }\end{array}$ & 1 & $\begin{array}{l}\text { The team is coherent with the } \\
\text { production organization }\end{array}$ & The team follows another organization \\
\cline { 2 - 4 } & 2 & $\begin{array}{l}\text { The members of the team want to } \\
\text { become experts of the problem }\end{array}$ & Some people do not become expert \\
\cline { 2 - 4 } & 3 & $\begin{array}{l}\text { The problem is divided between fields } \\
\text { of expertness. There is one expert for } \\
\text { every part of the problem }\end{array}$ & $\begin{array}{l}\text { The problem is not entirely covered by } \\
\text { expertness. There is a legitimized non- } \\
\text { expertness }\end{array}$ \\
\cline { 2 - 5 } & 4 & $\begin{array}{l}\text { The solution is legitimized by } \\
\text { expertness and approved by the non- } \\
\text { experts }\end{array}$ & The solution is collectively designed \\
\cline { 2 - 4 } $\begin{array}{l}\text { characterization } \\
\text { of the problem }\end{array}$ & 5 & $\begin{array}{l}\text { The problem is local } \\
\text { The problem is considered as known } \\
\text { and understood }\end{array}$ & $\begin{array}{l}\text { The problem has to be clarified and } \\
\text { measured }\end{array}$ \\
\cline { 2 - 4 } & 7 & $\begin{array}{l}\text { The parameters of the problem can be } \\
\text { easily measured }\end{array}$ & $\begin{array}{l}\text { There are new parameters to measure } \\
\text { and new measures to implement to } \\
\text { understand the problem }\end{array}$ \\
\hline
\end{tabular}




\begin{tabular}{|l|l|l|l|}
\hline & 8 & The problem is common in production & $\begin{array}{l}\text { The problem is revealed by an } \\
\text { unusual science in production }\end{array}$ \\
\hline approach & 9 & $\begin{array}{l}\text { The problem is solved using sciences } \\
\text { commonly used in production }\end{array}$ & $\begin{array}{l}\text { External sciences are needed to } \\
\text { address the question }\end{array}$ \\
\cline { 2 - 4 } & 10 & $\begin{array}{l}\text { The solution is tested according to a } \\
\text { validation of hypothesis }\end{array}$ & $\begin{array}{l}\text { The validation of initial hypothesis is } \\
\text { not enough. The approach is } \\
\text { exploratory. All the result of the tests } \\
\text { is taken into account }\end{array}$ \\
\cline { 2 - 5 } & 11 & Only the final solution is tested & $\begin{array}{l}\text { There are iterations in the tests; partial } \\
\text { solutions are tested }\end{array}$ \\
\cline { 2 - 5 } & 12 & $\begin{array}{l}\text { A surprising result is not taken into } \\
\text { account in the final solution }\end{array}$ & $\begin{array}{l}\text { The surprising results are integrated to } \\
\text { the design of the solution }\end{array}$ \\
\hline of the solution & 13 & $\begin{array}{l}\text { The solution is approved when it is } \\
\text { considered satisfying }\end{array}$ & $\begin{array}{l}\text { There is a continuous process of } \\
\text { improvement of the solution }\end{array}$ \\
\cline { 2 - 5 } & 14 & The rules are modified by high steps & $\begin{array}{l}\text { The experimental results continuously } \\
\text { come to modify the rules; }\end{array}$ \\
\cline { 2 - 5 } & 15 & The history of the process is not kept & $\begin{array}{l}\text { There are traces of the process of } \\
\text { designing the solution. }\end{array}$ \\
\cline { 2 - 4 } & 16 & $\begin{array}{l}\text { The solution is a existing method or } \\
\text { tool in production }\end{array}$ & $\begin{array}{l}\text { The solution has to be designed from } \\
\text { scratch }\end{array}$ \\
\hline
\end{tabular}

